\title{
A TRANSGRESSÃO SUBJETIVA EM UM ENSAIO COTIDIANO COMPORTAMENTAL
}

\author{
THE SUBJECTIVE TRANSGRESSION IN \\ A BEHAVIORAL EVERYDAY ESSAY
}

\author{
Caio Cesar Gomes
}

\section{RESUMO}

O tema de investigação do artigo é a subjetividade e visa compreender a relação entre novas aprendizagens e a transformação comportamental. Para desenvolver este estudo bibliográfico, o tema foi delimitado nas relações interpessoais, especificamente nas existentes nas relações conjugais. Foram priorizados os conceitos referentes à ecologia dos saberes, pensamento pós-moderno e do pensamento pós-abissal desenvolvidos por Boaventura de Souza Santos. Estes conceitos foram transferidos de seu patamar universal e aplicados no contexto íntimo, microssocial, da relação conjugal, como forma de perfilhar as possíveis transformações ocorridas nesta relação, decorrentes das alterações sociais e, a partir delas, compreender como estas são aprendida e transformadas em comportamentos. Conclui-se, embora reticente, que as transformações subjetivas ocorrem por novas aprendizagens, sejam estas de característica popular ou de conhecimento científico universal, havendo reciprocidade entre o aprender e o comportamento, no entanto, o tempo entre um e outro é excessivamente longo e imprevisível. Primeiro ocorre o novo aprendizado e, posteriormente, a possibilidade da sua manifestação em forma comportamental.

Palavras-chave: Subjetividade.Aprendizagem. Comportamento.

\section{ABSTRACT}

The investigation subject of this article is the subjectivity, and it aims to understand the relationship between new learnings and the behavioral transformation. To develop this 
bibliographic study, the subject was delimited through interpersonal relationships, specifically the conjugal ones. Concepts regarding the ecology of knowledge, postmodern thinking, and the abyssal thinking by Boaventura de Souza Santos were prioritized. These thoughts were transferred from their universal level and applied to the intimate, micro-social, conjugal context, as a way to profile the possible transformations that occur in this relationship, resulting from social alterations and, from them, to understand how they are learned and transformed in behaviors. It is possible to conclude, although reticently, that the subjective transformations occur through new learnings, with popular characteristics or with universal scientific knowledge, having reciprocity between learning and behavior, however, the time between one and another is excessively long and unpredictable. The new learning happens first, and then, the possibility of its manifestation in a behavioral way.

Keywords: Subjectivity. Learning. Behavior.

\section{A SUBJETIVIDADE EMERGENTE}

O que se passa na subjetividade das pessoas, quando elas aprendem? Quando aprendizados novos passam a fazer parte da subjetividade? Quando as pessoas dialogam sobre esses novos saberes? Quando estes devem transformar ou transformam comportamentos? Há séculos, talvez desde que o homem conseguiu pensar sobre a sua existência, existe a vontade de entender o significado disso. Essas indagações se tornaram um centro de investigações protuberantes da espécie. Afinal, o que vem a ser esse acontecimento biopsicossocial, que aceita e que processa essas vivências, dando significado à existência?

É uma interrogação complexa e deixar-se levar pelos meandros nela inerentes é correr o risco de divagar por um vasto campo de reflexões fascinantes, mas inapropriado para o momento. Isso porque, certamente, essa opção levaria a um distanciamento do propósito deste artigo, tornando impossível o retorno ao seu objetivo, que é bem mais delimitado, embora seja complexo também.

O tema central do artigo é a subjetividade, em sua condição de transformação. De maneira ainda mais precisa, em sua condição de superação dos preceitos que nela se instalam. A questão a ser respondida é: como a subjetividade se transforma no que se refere à constante construção de novos regulamentos que determinam o comportamento social? Até que ponto esses novos construtos implicam em transformações no comportamento? Ou seja, um acontecimento desta natureza - um aprendizado novo - pode ser considerado uma transformação subjetiva? E esse aprendizado implica, necessariamente, em uma transformação no comportamento?

Essa discursiva perpassa por constatações já obtidas, que se repetem desde as mais encantadoras e comoventes explanações psicanalíticas sobre as bases inconscientes constitutivas da personalidade até a constatação de que a colonização das sociedades ocidentais gerou verdades regulatórias, enraizadas de tal forma no pensamento coletivo planetário que hoje estão transformadas em paradigmas sociocognitivos difíceis de serem contrapostos. Isso ocorre mesmo quando constatados os danos causados por elas, tanto na ecologia, como na segregação das classes sociais, sinais evidentes de seus limites conceituais e operacionais. Desse modo, a afirmação hipotética que norteia as investigações 
deste artigo é a de que novos aprendizados levariam a mudanças no comportamento, mas, para que isso aconteça a contento, devem-se entender essas mudanças como faz Morin (2004, p. 21), quando se refere ao que ele define como a cabeça bem feita: "significa que [...] em vez de acumular o saber, é mais importante dispor ao mesmo tempo de uma aptidão geral para colocar e tratar os problemas; princípios organizadores que permitam ligar os saberes e lhes dar sentido".

O autor torna-se ainda mais enfático sobre o que vem a ser uma cabeça bem feita ao afirmar que, se bem feita, estaria "apta a organizar os conhecimentos e, com isso, evitar sua acumulação estéril” (MORIN, 2004, p. 24).

Afirmações como essas, embora não possam ser negadas, tendem a provocar sensações de inadequabilidade ao leitor, pois lhe dão a entender que os sujeitos com essas qualidades possuem tal desenvolvimento que, por definição, já excluem aqueles que desse patamar não fazem parte, ou seja, geram um ideal de funcionamento mental, invejável. No entanto, não existe comprovação de que esse estado seja possível e nem mesmo que seja o mais adequado. Essas inflexões originam-se da flexibilidade que caracterizam esse tipo de animosidade e, além disso, por não se referirem a aspectos como a capacidade de não se desfazer de preceitos já existentes, mesmo quando esses são utilizados para transformação de outros. Quando esse processamento acontece, os preceitos iniciais deixam de ser o que eram e passam a ser o que se tornam, mas sem que o preceito inicial seja transformado. $O$ exemplo do racismo pode ajudar na elucidação do que está sendo referido. Apesar do fato de esse ser admitido racionalmente como impróprio, muitos outros fatores psicológicos e sociais continuam agindo contrariamente a sua extinção. Dessa forma, entende-se que o fato de aprender algo novo não implica necessariamente que o algo velho irá, imediatamente, deixar de existir. Basta lembrar-se das resistências desencadeadas quando a ciência esclareceu que a Terra não era o centro do universo e muito menos do Sistema Solar.

Entende-se que, em plano ideário, é uma definição invejável e, de alguma maneira, desejável. No entanto, essa habilidade de desmontar-se e remontar-se ao mesmo tempo em que se experiencia o cotidiano e o formal na vida real, parece ser algo inapropriado, pois implica em um estado funcional mental como sendo produto de certo condicionamento, semelhante ao muscular, adquirido quando se frequenta regularmente uma academia de ginástica.

Há plena certeza de que não é assim que o ser humano se constrói e se desenvolve durante a sua existência, embora ainda não se saiba exatamente como isso acontece. Muitos fatores intermedeiam o conhecimento adquirido no dia a dia, desde a alimentação, a habitação, a acessibilidade à cultura de forma geral, sem se excluírem as tendências ideológicas que contornam a verdade estabelecida precocemente no seio familiar. Todas essas influências estarão presentes no processo, na vontade de conhecer e na disponibilidade de querer manifestar essas transformações via comportamento.

É provável, baseando-se na constatação de que não existe uma verdade absoluta sobre nada, nem mesmo sobre essa estéril afirmativa que acaba de ser feita, que seja a condição de aprendizagens múltiplas a mais salutar e, quem sabe, a mais eficiente na elucidação dos fenômenos. Essa forma parece conter a possibilidade da inclusão das diferentes formas de interpretar todo e qualquer fenômeno e, com isso, de favorecer a 
inclusão das diferentes pessoas no mundo objetivo. Essas formas plurais coadunam a possibilidade de coabitarem o mesmo espaço social e psicológico, sem que uma tenha de excluir a outra, ao contrário, entendendo que a forma da verdade a ser atingida está inserida nessa condição, ou seja, ela está distribuída em cada uma dessas diferentes interpretações do fenômeno em questão, seja ele qual for.

A inclusão de diversas formas de conhecimentos interagindo de forma integrada e compartilhada é a maneira como Santos e Menezes (2009) entende ser possível a construção de um novo conceito epistemológico. A inclusão desses saberes contribui para construção do conhecimento, cada qual com os seus componentes epistemológicos, pois é nas diferenças existentes entre eles que cada um revela as facetas do fenômeno investigado.

Santos (1987) levanta essa discussão em seu livro Um discurso sobre as ciências, no qual questiona os fundamentos da ciência moderna; analisa os rumos que essa tem dado à evolução do conhecimento e evidencia os resultados, frutos da aplicabilidade desses no mundo real. A partir dessa análise, conclui que não pode ser negada a importância desse conhecimento, embora ele não responda adequadamente a muitas demandas atuais da sociedade. Santos (2002) lembra e, ao mesmo tempo, indaga sobre a influência, atualmente ausente, dos conhecimentos que desapareceram durante colonização do planeta, nos séculos das grandes descobertas, efetivado tal fato pelos conquistadores na cultura dos que habitavam as novas terras.

O autor denomina epistemicídio o processo de aculturalização realizado nos povos que viviam naquelas regiões. Não houve consideração alguma aos seus princípios, fossem estes morais, éticos, religiosos ou ao conhecimento que portavam sobre a natureza. Nada importou, todos sucumbiram ao que neles foi implantado a partir do conhecimento europeu. Ao resgatar essas ações históricas, fica implícita a falta que esses conhecimentos podem fazer atualmente para equalizar a maneira como a ciência moderna tem lidado com a natureza e com as sociedades.

Uma das suas abordagens, talvez a mais importante existente nas obras literárias de Santos, citadas neste artigo, refere-se à distinção, que ele traz para discussão, sobre o que vem a ser o conhecimento pós-moderno em relação ao conhecimento pós-colonial (SANTOS, 2004). Nesse contraste, ele destaca que o primeiro refere-se à continuidade da hegemonia dos princípios da ciência moderna (cartesiana), sem questionar os procedimentos utilizados e nem os resultados que esse modelo de fazer ciência tem trazido às questões ecológicas e nem para os fenômenos sociais. Essa noção de pós-modernidade não considera a necessidade do resgate epistemológico das culturas dizimadas, conforme já foi exposto. Já o conhecimento pós-colonial contempla essa necessidade, considera importante o resgate desses conhecimentos, até então perdidos, por entender que, no resgate do que ainda é alcançável desse conhecimento estão incluídas novas formas de a ciência lidar melhor com a natureza e com a humanidade, e, portanto, quem sabe, esta se torne mais capaz de contribuir para amenizar o dano já constituído.

Santos e Menezes (2009) se referem a resgate como epistemologias do sul, ou seja, o resgate daquele conhecimento que deixou de fazer parte da epistemologia planetária como decorrência da ação e do entendimento dos colonizadores de que ele seria desprezível, atrasado e não válido à cultura colonizadora. O conhecimento, que deveria predominar para aqueles, era o que eles portavam em sua cultura, ou seja, embrionário daquele que 
hoje prevalece. Nesse conhecimento, constata-se que ele contém não só todas as coisas maravilhosas que nos proporciona, mas também é ator principal da maior devastação da natureza e da injusta segregação social.

A evolução, no pensar de Santos (1987) e Santos e Menezes (2009), contribui para que se entenda o viés que é dado neste artigo, quando o autor se refere à transformação provocada na subjetividade decorrente da evolução do conhecimento. Um mundo se apresenta quando se pode olhá-lo sobre a lente epistemológica da modernidade. Um mundo necessitado de mais ciência, de mais recortes e de mais aprofundamentos segmentados, na perspectiva de que, num dado momento, seja possível unir todas as porções e todas as suas partículas, constituindo uma espécie de resolução de uma equação final. Como resultado dessa resolução, a obtenção dos procedimentos utilizáveis para que o planeta e as sociedades e seus habitantes possam ser mais bem tratados, considerando - em hipótese fictícia - que o conhecimento total seja conquistado.

Na outra concepção, na qual todos os conhecimentos contribuem para a evolução equalizada do planeta, haveria melhor engajamento do homem com a natureza e melhor integração nas suas relações sociais, o que implicaria no que ele denomina de ecologia dos saberes (SANTOS, 2008), princípio que considera importante todas as formas de conhecimento, as quais devem estar presentes na interpretação dos fenômenos, porque cada qual possui a sua forma de desvendá-lo e, portanto, de importância.

No entanto, o que se observa no cenário empírico da vida social é que muitos dos conhecimentos originários do viés moderno permanecem, seja no desenvolvimento científico, seja no desenvolvimento dos demais conhecimentos. Esse ainda classifica e determina o que é verdade ou conhecimento válido e os demais ainda margeiam os contornos científicos. Na compreensão desses acontecimentos, permanecem as dúvidas sobre o que é e o que não é conhecimento válido. É nesse misterioso campo que as investigações deste artigo adentram. Interessado em desvelar o que acontece com as sociedades que, mesmo conhecendo outras verdades sobre a realidade que experimentam, continuam a sobrepor as antigas, mantêm o conhecimento tradicional, mesmo já superado, considerando-o como verdadeiro. Isso ocorre em resistência às novidades e em aproximação ao conceito de Durkheim (1983), classificando este fenômeno social como pré-noções existentes nas sociedades. As ações destas parecem invisíveis, contudo se manifestam como uma espécie de campo de força previamente instalado e, independentemente da vontade humana, são capazes de promover modelações nos comportamentos daqueles que nelas habitam.

Retorna-se, então, à mesma questão, ou seja, como acontece a evolução de novos princípios científicos e de novos valores morais se suas práticas continuam orientadas por princípios originários de seus ancestrais?

\section{O SUBJETIVO TRANSGREDIDO NO COTIDIANO}

Ao se relacionar o conhecimento científico com o conhecimento comum e considerálos como resultado da concepção de mundo pós-moderno, constata-se que ambos, pelo menos em teoria, têm provocado alterações nos comportamentos sociais. Assim, serão feitas algumas alocações do mundo cotidiano que poderão parecer forçadas, no entanto, 
como se trata de cenários comuns, é provável que o leitor não tenha dificuldades em identificá-las e nem em compreender as intenções do autor, pois fazem parte da experiência da sua vida.

Transformações comportamentais evidenciam, de certa forma, as transformações que estão ocorrendo na intimidade. Giddens (1993, p.18) se refere a esse assunto analisando "mudança social e comportamento sexual". O autor relata, como resultados de suas pesquisas, a opinião de mulheres sobre a sexualidade, demonstrando que esse comportamento tem se modificado com a importância dada à virgindade. Gideens (1993, p. 19) escreve que as "garotas acham que têm o direito de se envolver na atividade sexual, incluindo a relação sexual, em qualquer idade que Ihes pareça apropriada". As garotas, segundo Rubin (apud GIDDENS, 1993, p. 21), "falam uma linguagem de romance e compromisso que reconhece a natureza potencialmente finita de seus envolvimentos sexuais anteriores", na continuidade das relações afetivas atuais. As mulheres, menciona o autor, "esperam tanto receber quanto proporcionar prazer sexual".

Em explicações sobre essas modificações no comportamento, Giddens (1996) avança para os modelos estruturais de famílias, descrevendo como as formas predominantes dos sistemas ideológicos vigentes influenciam e até determinam a distribuição de poderes existentes na dinâmica intrafamiliar. Constata que certas regiões, nas quais predominam formas autoritárias: a arbitrariedade e o forte alinhamento vertical na distribuição das forças de mando propiciam o surgimento de famílias com estruturação dinâmica semelhantes. Ocorre o contrário em locais onde predomina a democracia. Nesses, identificam-se famílias com organização democrática e distribuição linear do poder.

Essas constatações são observadas no cotidiano, talvez não exatamente dessa maneira, mas há formas de distribuição de poder mais amenas em que predomina a democracia, e não o autoritarismo. Contudo, a questão não se esgota na observação do comportamento manifesto, mas na dimensão menos observável diretamente, a qual nem por isso é menos influente na determinação daquele, pois são acontecimentos no coletivo subjetivo.

Como isso pode ajudar a esclarecer sobre o lugar desempenhado pelo conhecimento na determinação de comportamentos, sejam estes convencionais ou de vanguarda? De fato, interessa mesmo é este último tipo, porque se está averiguando como o conhecimento pode gerar novos comportamentos. E essa é a indagação a que o autor se atém, pois, como tem sido referido, ele está interessado em compreender como alguns comportamentos resistem às alterações epistemológicas. Por mais que se saiba que passar por debaixo de uma escada não causa azar, por exemplo, poucas pessoas se atrevem a fazer isso sem um resquício de dúvida.

O iluminismo (ADORNO, 1980), ao tentar desdogmatizar a natureza, provoca um novo comportamento da humanidade em relação a essa. Isso é um fato inquestionável, mas até que ponto ele, de fato, provocou mudanças essenciais no comportamento social, bem como até onde essas transformações ocorreram em nível manifesto, embora ainda mantivessem crenças irracionais guardadas em lojas de memórias filogenéticas e, portanto, alocadas ativamente na subjetividade?

Essas indagações provocam a utilização de mais um exemplo para se elucidarem esses processos inesgotáveis sobre o comportamento social, ou seja, qual é a distância 
existente entre o mundo subjetivo e o mundo social? Será possível um dia vivê-los na integralidade, sem que um sombreie ao outro? Talvez, nesse dia, haja um ser humano autêntico, se é que se pode esperar que tal venha a acontecer. Além disso, teria de ser analisado se isso é uma necessidade da espécie. Contudo, esses rumos não são adequados para o atual propósito, mas sem dúvidas são indagações facinantes.

O cenário utilizado para essa finalidade exemplar será o do relacionamento familiar, centrado no relacionamento conjugal, por considerar este setting em permanente discussão e em constante redimensionamento, no entanto, permeado de ambiguidades e de avaliações inconclusas sobre as suas dimensões. Por outro lado, o relacionamento conjugal se estende para além do setting familiar, pois envolve o ambiente do trabalho e das amizades, além da subjetividade de cada um dos integrantes, o qual se modifica conforme as determinações evolutivas, psicológicas e biológicas, assim como pelos estímulos sociais do cotidiano e da aprendizagem científica.

Circunscrita ou ampliada por essas dimensões, a relação conjugal contempla um cenário muito mais amplo que o relacionamento entre dois atores apaixonados. Estes atores, por sua vez, estão inseridos em uma sociedade que também evolui, à medida que novos conhecimentos são divulgados sob a forma de normatizações comportamentais ou em estruturas tecnológicas, as quais, notadamente, preenchem os espectros ambientais.

A mulher que almeja a sua emancipação e reconhecimento como cidadã com os mesmos direitos que o homem também se faz presente nessa relação. Da mesma maneira, o homem, destronado de sua predominância imperial, também está ali com todos os seus conflitos e todas as ambiguidades que caracterizam o seu momento social.

É no entremeio desses acontecimentos que as dúvidas circundam sobre como as transformações subjetivas são promovidas por esse cenário, permeado de novos acontecimentos objetivos e subjetivos. E mais uma vez retorna a pergunta: esses fatos se transformam em novos comportamentos ou simplesmente são apreendidos? E eles não levam a transformações?

Considerando-se a emancipação feminina como um fato social, praticamente acabado, entende-se, todavia, que, quando algum acontecimento abala as relações desses atores, isso desencadeia intensas e insensatas turbulências, dando a entender que não ocorreram transformações, mas o contrário. Por exemplo: o homem que aceita a emancipação feminina ao viver, na sua relação conjugal, o papel de coadjuvante, devido à mulher ter conquistado um melhor lugar que ele no trabalho ou na hierarquia social, ainda reage como se tivesse sido ultrajado.

Contudo, o discurso, quando está entre os iguais ou perante alguém, que de alguma forma avalia o seu comportamento, é bem diferente, como se essa transposição fosse plenamente aceita por ele, no caso o homem. É nesse lugar psicossocial que parece alojarse a dúvida se o conhecimento pode ou não transformar o comportamento. O homem tem consciência de que a mulher pode ocupar um lugar diferenciado e que se, porventura, esse vier associado a um ganho econômico maior, melhor ainda, pois a vida de ambos poderá ser mais confortável e mais bem desfrutada, mas viver isso ainda é desconfortável.

A mulher, por sua vez, deve passar por conflitos semelhantes, pois até onde ela desfruta desse novo lugar e até onde ela pode se julgar inadequada por ir de encontro àquele com quem divide a sua convivência interpessoal mais íntima. Ela é culpada por progredir? Até 
quando e qual o limite para entender se deve suportar esse desconforto ou se deve romper a relação para poder se desenvolver como pessoa? Onde foram parar as questões afetivas e histórias de vida que tiveram em comum e os planos futuros? (GIDDENS, 2002).

Como a mulher age quando há um convite para desfrutar de uma happy hour com um amigo, se ela tem um relacionamento afetivo com outra pessoa, e como esta outra pessoa vive tal variável em sua intimidade? Deve compartilhar com uma terceira pessoa um espaço social que seria restrito ao casal? Considerando que, em sociedade, ainda um homem vive maritalmente com uma mulher e uma mulher com um homem, pelo menos em comportamento manifesto, a monogamia permanece vigente.

Se se explicitasse essas vivências subjetivas, os valores machistas mostrar-se-iam superados ou eles ainda existiriam tanto na subjetividade feminina como na masculina?

Narra-se em um conto que um casal de boa condição econômica, por opção e certa acomodação, vivia em uma pequena comunidade. Tomados pelo tédio da rotina da pequena cidade, resolveram mudar para uma cidade maior, na qual seu poder aquisitivo não permitiria as benesses que obtinham em sua cidade, mas mesmo assim, mudaram-se. Para não perderem a qualidade de vida, resolveram que viveriam entre eles e que desfrutariam somente das oportunidades culturais que a cidade lhes proporcionasse.

No entanto, assim que chegaram à cidade maior, esses planos foram esquecidos. A esposa viu-se em um mundo tão maravilhoso e novo para ela, que a tornava tão feliz, com tantas coisas interessantes a descobrir que logo, ainda que inconscientemente, renegou todas as suas convicções passadas e todos os seus planos de viver uma vida restrita. Sentia que sua vida ainda não havia começado. Esta que se apresentava é que era a sua verdadeira vida. O amor pelo seu marido tornara-se mais tranquilo e não pensava se ele ainda a amava ou não. Essas dúvidas não surgiam na pacata vida que levavam. Percebia que, além de seu marido a amar como antes, agora também a admirava. Quando recebiam amigos, ele elogiava as suas qualidades domésticas. Tudo parecia estar muito bem. Os dois viviam uma nova lua de mel. Alegres e juntos desfrutavam desse regozijo compartilhado.

Certa vez, uma tia do marido convidou a esposa para ir a um baile, pois conviviam há algum tempo, mas nunca os vira desfrutando dos acontecimentos festivos. A esposa, notando o ar de concordância do marido, respondeu que sim. Gostaria muito de ir a um baile. $\mathrm{Na}$ intimidade, estavam ela e o marido com dúvidas, pois haviam combinado que não participariam de acontecimentos sociais, só de eventos culturais.

Para ela, o baile foi maravilhoso, sentia-se, durante o festejo, como se fosse a atração principal, como se tudo acontecesse para ela. Durante o baile, recebera muitos elogios e tudo the parecia novo e espetacular.

Notou então que, no início, após passarem a frequentar esses lugares, o marido a acompanhava com evidente prazer e felicidade, mas com o decorrer do tempo, ele passou a entediar-se e a irritar-se com aquele modo de vida. Ela, no entanto, estava ofuscada com o novo estilo de vida. Sentia-se muito bem pelo fato de poder, naquele mundo novo, não só sentir-se igual ao esposo, mas até mesmo superior e, com isso, poder gostar dele mais livremente e até mais do que antes, mas não entendia o que ele via de inconveniente na vida em sociedade. Enquanto ela se sentia orgulhosa por ser notada e valorizada, ele parecia constrangido em admitir perante a multidão que era seu marido e acabava se afastando, sumia no meio dos demais. Ela não entendia o que estava acontecendo com ele. 
Não tardou para que dúvidas e inseguranças surgissem entre eles e discordâncias verbais fossem explicitadas. Ofensas dissimuladas e ressentimentos provocados por essas manifestações tornaram-se corriqueiros a ponto de macular os sentimentos de um com o outro. Não entendiam o que se passava e marcas foram sobrepondo-se no afeto que os unia. Combinaram, então, que voltariam à pequena cidade e viveriam longe dessa vida em sociedade que lhes havia perturbado o convívio que até então tinham mantido.

Porém, davam-se conta de que não Ihes adiantava mais voltar. Nada mudaria. Suas vidas não seriam mais as mesmas, e os sentimentos já haviam sido modificados. Olhavam um para o outro e, mesmo enxergando os mesmos rostos, as pessoas que ali estavam já não eram mais as mesmas. O relacionamento mudara radicalmente. Era como se eles sentissem o abismo que os separava e temessem se aproximar dele. Evitavam discutir suas diferenças. Ela o entendia como orgulhoso e irascível, e ele acreditava que ela não poderia mais passar sem a vida em sociedade. Faziam comparações das suas vidas com outras pessoas e, secretamente, teciam juízos um sobre o outro. Um romance que parecia se desenrolar num clima afetivo e tranquilo, agora se encontrava abalado por circunstâncias sociais, diferentes das corriqueiras, que eles passaram a experimentar quando mudaram de uma cidade pequena e pacata para uma cidade maior, envolvendo outros tipos de oportunidades.

Esse fragmento transcreve parte do que envolve o relacionamento conjugal entre duas pessoas e contém situações suficientes para exemplificar como as novas experiências e, com elas, a aquisição de novos aprendizados, oriundos de um complexo cenário constituído por estímulos sociais diversos, contrastam com conceitos e valores previamente alocados na subjetividade e como esses são processados por seus protagonistas.

\section{ANÁLISE E DISCUSSÃO}

Obviamente que Santos (2002, 2004, 2005, 2008) e Santos e Menezes (2009), nos diversos textos citados, referem-se ao conhecimento universal, planetário, ou seja, está envolto com os macroenigmas epistemológicos e não com a particularidade de um caso conjugal, como neste artigo se ocupa o autor. No entanto, não há uma distância clara e nem uma diferenciação nítida sobre o início e o término da influência desse conhecimento na vida cotidiana. É bem provável que o rumo do conhecimento científico, após sua divulgação e utilização pelas sociedades de origem e pelas demais, seja o de se transformar, gradualmente, em conhecimento popular. Portanto, a aplicação deste macroconhecimento, para compreender uma partícula social específica, parece adequada, desde que ressaltada essa condição.

Assim, considera-se que a libertação feminina e todas as suas implicações estejam sendo vividas na maioria das sociedades ocidentais, como de fato está acontecendo. Contudo, na intimidade desses viventes, pode ser que ainda ocorram reações de estranheza quando um cônjuge se transforma, no sentido como o do fragmento de texto anterior, ou quando um deles tem de dividir o comportamento social com uma terceira pessoa, como no caso da happy hour. Por que isso acontece?

Várias respostas podem ser extraídas desse contexto. Pode-se entender como a continuidade da luta de classes entre o homem e a mulher, referida por Engels (1982), ou 
ainda como uma tentativa de superação à castração, à qual se refere Freud (1987) ou, ainda, como movimento social, no qual a (re)modelação da matriz machista estaria em construção tanto no homem como na mulher, conforme Touraine (2007). Várias outras interpretações poderiam ser extraídas desse exemplo, mas o que ele nos evidencia é que, para a época em que essa trama ocorreu, essas manifestações entre um homem e uma mulher, em seu convívio íntimo, poderiam ser coerentes, pois os valores e a forma esperada para que um homem e uma mulher se relacionassem deveria preencher esses pré-requisitos. No entanto, o fragmento de texto citado é de Tolstói (2009) e aborda a convivência conjugal do século XVIII, mais precisamente do ano de 1859 , quando foi publicado pela primeira vez.

A discussão, portanto, não é sobre a qualidade da novela, mas ao conteúdo existente no relacionamento entre homem e mulher, em seu convívio íntimo, naquela época e que não parece tão diferente da época atual. Quase três séculos se passaram.

O que tem a ver esse exemplo com o questionamento sobre os princípios da ciência moderna, com a ecologia dos saberes, com a noção pós-colonial e com o pensamento pósabissal ${ }^{1}$ ?

\section{ENSAIO DE UMA CONCLUSÃO}

Como expus anteriormente, não existe uma distância mensurável entre o conhecimento científico e o conhecimento popular que possa identificar precisamente o início de um e o término de outro, embora sejam sensivelmente diferentes.

Quando os preceitos do conhecimento científico são questionados, colocam-se igualmente em questão, junto a esses, os preceitos que regem as sociedades, pois estas se regulam também por meio deles. A ecologia dos saberes predispõe certa igualdade entre os preceitos, considerando que todos contêm algo válido e importante, conforme o fenômeno em análise e discussão. De uma forma expansiva, eles acabam invadindo os costumes sociais e as formas como as interações se estabelecem, pois fica implícita a importância de todos os saberes na interpretação dos acontecimentos sociais. Assim, idéias de inclusão social e de reciprocidade vão sendo disseminadas.

Do mesmo modo, as noções de pós-colonialismo alertam para os saberes oprimidos e excluídos de validação e de importância, mas nem por isso deixaram de existir ou de fato não têm importância. Há aqueles que não se pronunciam explicitamente, mas isso não quer dizer que não existam ou que não contribuam no rumo dos acontecimentos sociais.

O pensamento pós-abissal ressalta, mais uma vez e enfaticamente, que pode existir mais de uma verdade na análise de um mesmo fenômeno social ou natural. Dessa maneira, indica que tanto uma revelação como outra sobre um mesmo aspecto podem significar uma versão diferente a respeito de uma mesma realidade, sem que uma exclua a outra.

Ao se utilizar a compreensão desses macroprocessamentos para se analisar um microacontecimento, como é o caso de um relacionamento conjugal, obter-se-iam algumas conclusões e, dentro destas, o que parece significante é que nem todo o conhecimento adquirido é diretamente assimilado, praticado e expresso pelo comportamento.

\footnotetext{
${ }^{1}$ Considera inesgotável a diversidade do mundo e desprovida de uma epistemologia adequada, de modo que a diversidade epistemológica do mundo está por ser construída.
} 
Entre o homem e a mulher pode ser constatado o discurso generalizado sobre a emancipação de ambos, mas, no convívio íntimo e mesmo no desempenho social, parece existir uma espécie de regra aprisionante, que os coloca em situação de impedimento em muitas das suas intenções e realizações.

É conclusivo, no entanto, embora não de modo definitivo, que não dá para desconsiderar que existem influências do conhecimento macro, ou seja, da evolução do conhecimento científico no comportamento microcósmico das experiências sociais e nem de que não ocorram constantes transformações no comportamento social, em qualquer nível da sociedade e tampouco se pode desconsiderar a influência delas na constituição da subjetividade, porém essas repercussões se dão, em princípio e prioritariamente, em nível cognitivo e somente com o passar do tempo e com a assimilação gradual e lenta é que se transferem para o comportamento social manifesto.

Dessa forma, as questões iniciais do artigo, embora parcialmente respondidas, permanecem em aberto. O que se passa na subjetividade das pessoas, quando elas aprendem? Quando aprendizados novos passam a fazer parte da subjetividade? Quando as pessoas dialogam sobre estes novos saberes? Quando esses devem transformar ou transformam os seus comportamentos? Finalmente, quando se conhecerá mais sobre esses processos?

\section{REFERÊNCIAS BIBLIOGRÁFICAS}

ADORNO, Theodor W. Textos escolhidos. São Paulo: Abril Cultural, 1980. (Os Pensadores)

DURKHEIM, Émile. Da divisão do trabalho social: as regras do método sociológico; o suicídio; as formas elementares da vida religiosa. 2. ed. São Paulo: Abril Cultural, 1983. (os pensadores)

ENGELS, Friedrich. A origem da família, da propriedade privada e do estado. 8. ed. Rio de Janeiro: Civilização Brasileira, 1982.

FREUD, Sigmund. Introdução à psicanálise: in obras completas. v. XVI. São Paulo: Abril, 1987.

GIDDENS, Anthony. A transformação da intimidade: sexualidade, amor \& erotismo nas sociedades modernas. São Paulo: Ed. da Universidade Estadual, 1993.

Para além da esquerda e da direita: o futuro da política radical. São Paulo: Ed. da Universidade Estadual Paulista, 1996.

Modernidade e identidade. Rio de Janeiro: Jorge Zahar, 2002.

MORIN, Edgar. A cabeça bem-feita: repensar a reforma, reformar o pensamento. 10. ed. Rio de Janeiro: Bertrand Brasil, 2004.

SANTOS, Boaventura de Souza. A crítica da razão indolente: contra o desperdício da experiência. São Paulo: Cortez, 2002.

SANTOS, Boaventura de Souza. Do pós-moderno ao pós-colonial. Conferência de abertura do congresso Lusoafro-brasileiro de ciências sociais. Coimbra, set. 2004. 
A TRANSGRESSÃO SUBJETIVA EM UM ENSAIO COTIDIANO COMPORTAMENTAL

SANTOS, Boaventura de Souza. Um discurso sobre as ciências. São Paulo: Cortez , 2005.

SANTOS, Boaventura de Souza. A gramática do tempo: para uma nova cultura política. 2. ed. São Paulo: Cortez, 2008.

SANTOS, Boaventura de Souza; MENESES, Maria Paula (Org.). Epistemologias do sul. Coimbra: Almeida SA, 2009.

TOLSTÓI, Leon. A felicidade conjugal. Porto Alegre: L\&PM, 2009.

TOURAINE, Alain. Um novo paradigma: para compreender o mundo de hoje. 3. ed. Petrópolis: Vozes, 2007. 